\title{
Autun et Perrecy-les-Forges (Saône-et-Loire)
}

\section{Sylvie Balcon-Berry et Walter Berry}

\section{(2) OpenEdition}

\section{Journals}

\section{Édition électronique}

URL : https://journals.openedition.org/cem/2952

DOI : $10.4000 /$ cem.2952

ISSN : 1954-3093

\section{Éditeur}

Centre d'études médiévales Saint-Germain d'Auxerre

\section{Édition imprimée}

Date de publication : 15 août 2003

ISSN : 1623-5770

\section{Référence électronique}

Sylvie Balcon-Berry et Walter Berry, « Autun et Perrecy-les-Forges (Saône-et-Loire) », Bulletin du centre d'études médiévales d'Auxerre | BUCEMA [En ligne], 7 | 2003, mis en ligne le 19 octobre 2007, consulté le 22 septembre 2022. URL : http://journals.openedition.org/cem/2952 ; DOI : https://doi.org/10.4000/ cem. 2952

\section{Ce document a été généré automatiquement le 22 septembre 2022}

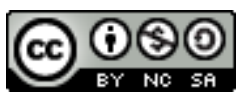

Creative Commons - Attribution - Pas d'Utilisation Commerciale - Partage dans les Mêmes Conditions 4.0 International - CC BY-NC-SA 4.0

https://creativecommons.org/licenses/by-nc-sa/4.0/ 


\title{
Autun et Perrecy-les-Forges (Saône- et-Loire)
}

\author{
Sylvie Balcon-Berry et Walter Berry
}

Autun

1 À Autun, deux opérations ont été menées en parallèle. Il s'agit tout d'abord de l'étude archéologique de l'ancienne "salle capitulaire" du cloître canonial de Saint-Nazaire, puis des relevés du porche de la cathédrale Saint-Lazare.

Étude archéologique de Saint-Nazaire

2 En 2002, s'est poursuivie l'analyse de l'enfoui et des élévations de l'ancienne "salle capitulaire" 1 située à l'est de la galerie orientale. Il a notamment été possible de dégager plus amplement les parties inférieures du mur ouest caractérisé par la présence de deux ouvertures bouchées, l'une au sud et l'autre plus au nord. Malgré un décaissement sévère des niveaux archéologiques associés à cette paroi et déjà observé en 2001 plus à l'est de l'espace d'étude, l'analyse de cette maçonnerie conjuguée à d'autres structures mises au jour a permis de valider l'hypothèse d'une réalisation de ce mur au milieu du IX ${ }^{\mathrm{e}}$ siècle. Le réexamen d'une fouille ancienne pratiquée dans une zone très limitée de la galerie est a d'autre part renforcé cette présomption et laisse aussi envisager l'implantation de bâtiments claustraux en bois dès la première moitié $\mathrm{du} \mathrm{IX}^{\mathrm{e}}$ siècle. Cette dernière assomption devrait être confirmée ou infirmée lors de l'ultime campagne sur ce site, celle de 2003, qui touchera la totalité de la galerie orientale. Signalons en dernier lieu qu'afin de compléter la documentation sur le bâti, des relevés de la partie inférieure du mur extérieur sud de l'ancien réfectoire ont été effectués en avril 2003 grâce à l'aimable autorisation des nouveaux propriétaires ${ }^{2}$.

Relevés du porche de Saint-Lazare d'Autun

3 Avec l'accord de M. Frédéric Didier, architecte en chef des Monuments historiques, des relevés de l'enveloppe extérieure du porche de la cathédrale Saint-Lazare d'Autun ont été entrepris en avril 2002, et ce parallèlement à une grande campagne de restauration ${ }^{3}$. Au cours de l'été, les salles supérieures ont d'autre part été investies. Il a ainsi été possible d'enregistrer la quasi-totalité des parements de cette structure d'entrée et de confronter les observations extérieures avec les observations intérieures. Des dessins 
méticuleux des chapiteaux et des bases présents sur cette partie du bâtiment, ainsi que d'un tympan localisé dans une salle haute, ont été réalisés ${ }^{4}$. S'il est encore trop tôt pour tirer des conclusions, on peut toutefois signaler que cette lecture précise du porche de Saint-Lazare, trop souvent négligé par les chercheurs, remet en cause la grande homogénéité qui lui est généralement attribuée. Des grandes phases de constructions sont bien perceptibles à travers l'analyse des maçonneries et la distribution des trous de boulin. De plus, des repentirs ont été mis en valeur. Enfin, des chapiteaux provenant probablement des tours complètement reconstruites au XIXe siècle et entreposés dans divers endroits de la cathédrale, viennent d'être redécouverts et seront présentés dans la prochaine exposition du Musée Rolin ${ }^{5}$.

Perrecy-les-Forges

4 Des relevés entrepris par une équipe d'architectes de Berlin, dans le cadre des activités du CEP (Centre international d'études des patrimoines culturels en CharolaisBrionnais) de Saint-Christophe-en-Brionnais, ont donné l'opportunité de découvrir, en 2001, une structure totalement inédite et située au troisième niveau du porche de l'ancienne église priorale de Perrecy-les-Forges. Cet élément de plus de quatre mètres de haut (jusqu'au départ d'une voûte brisée) et de dix mètres de longueur, correspond à l'amorce d'une chapelle haute, encadrée de deux tours, jamais achevée et à dater, si l'on se fonde sur l'analyse stylistique des chapiteaux qui l'agrémentent, du milieu du XII siècle. Un enregistrement de cette élévation a été mené en été $2002^{6}$, mais une analyse détaillée de l'espace muséal situé juste au-dessous ainsi que du célèbre rez-de-chaussée permettrait de compléter et d'affiner nos données. Il serait ainsi possible de confirmer l'hypothèse actuelle qui voit dans cette salle haute une volonté de reconstruire entièrement le reste de l'édifice, fleuron de l'art roman et remontant au $\mathrm{XI}^{\mathrm{e}}$ siècle.

\section{NOTES}

1.S. BALCON et W. BERRY, "Autun (Saône-et-Loire) étude archéologique du cloître SaintNazaire", Études et travaux, 6, 2001-2002, p. 14-16. Ce site correspond au chantier-école de l'Université de Paris IV-Sorbonne et les étudiants sont accueillis par la Mairie d'Autun.

2.M. et Mme Lequime que nous tenons ici à remercier. Deux étudiantes de l'Université de Lyon II ont participé à cette opération (Audrey Badois et Armelle Prévost).

3.Avec des étudiants de l'Université de Paris IV-Sorbonne, notamment Amélie Béguin, Christophe Besnier et Vincent Marchaisseau.

4.Étude conduite par Jim Erwin. Merci à M. André Strasberg, conservateur adjoint au Musée Rolin, de nous avoir facilité l'accès aux parties hautes.

5.Exposition faisant suite à celle initiée à Auxerre en 1999 et intitulée : Prémices et floraison de l'art roman à Autun et dans l'Autunois (20 juin-29 septembre 2003).

6.Merci au Maire de Perrecy-les-Forges d'avoir permis ce travail. L'équipe était composée des mêmes personnes qu'à Saint-Lazare. 
INDEX

Index géographique : France/Autun, France/Perrecy-les-Forges

Mots-clés : Saint-Lazare d'Autun, Saint-Nazaire d'Autun 